\title{
"Shitty Automation": Art, Artificial Intelligence, Humans in the Loop
}

\author{
KRIS PAULSEN \\ Associate Professor, The Ohio State University
}

\begin{abstract}
This essay adapts the concept of "shitty automation," developed by Brian Merchant to name frustrating experiences with automated systems, to describe how human input - our labor, bodies, biases, prejudices, and desires — remains invisibly present in automated systems. Tracing a lineage of automation from Jacques de Vaucanson's Canard Digérateur (1739) and Wolfgang von Kempelen's mechanical Turk (1770) to contemporary artist Trevor Paglen, who uses Generative Adversarial Networks (GANs) to create artworks, this essay considers how humans "stay in the loop" in automation and what "shitty automation" reveals about human culture, our desires, and the evolution of AI.
\end{abstract}

\section{INTRODUCTION}

In 1739, Jacques de Vaucanson, the French inventor already known for his extraordinary clockwork androids, debuted a new automaton. While his Flute Player (1738) could merely perform twelve melodies on a standard flute just as a human musician would, with skin-covered fingers and breath from hidden bellows, his new invention, Canard Digérateur (Digesting Duck) could do something more: it could shit. ${ }^{1}$ [Figure 1] The life-sized, gold-plated creature was a marvel of naturalistic movement. It muddled water with its beak, reared on its legs, and quacked convincingly. Vaucanson claimed, and it was widely believed, that he had reproduced the duck in full anatomical detail, including its digestive system. The creature would eat from one's hand and then evacuate its robotic bowels after the meal made its way through an internal "chemical laboratory." The inventor did not claim to reap the benefits of the process, such as extracting energy, nourishment, or sustenance. ${ }^{2}$ Vaucanson's purpose here seemed to be the pursuit of a kind of unnecessary - even useless - labor for pure interest and delight. ${ }^{3}$ Perhaps, then, Vaucanson's art was in the duck's gratuitous excrement as much as in its precision clockwork. ${ }^{4}$ 


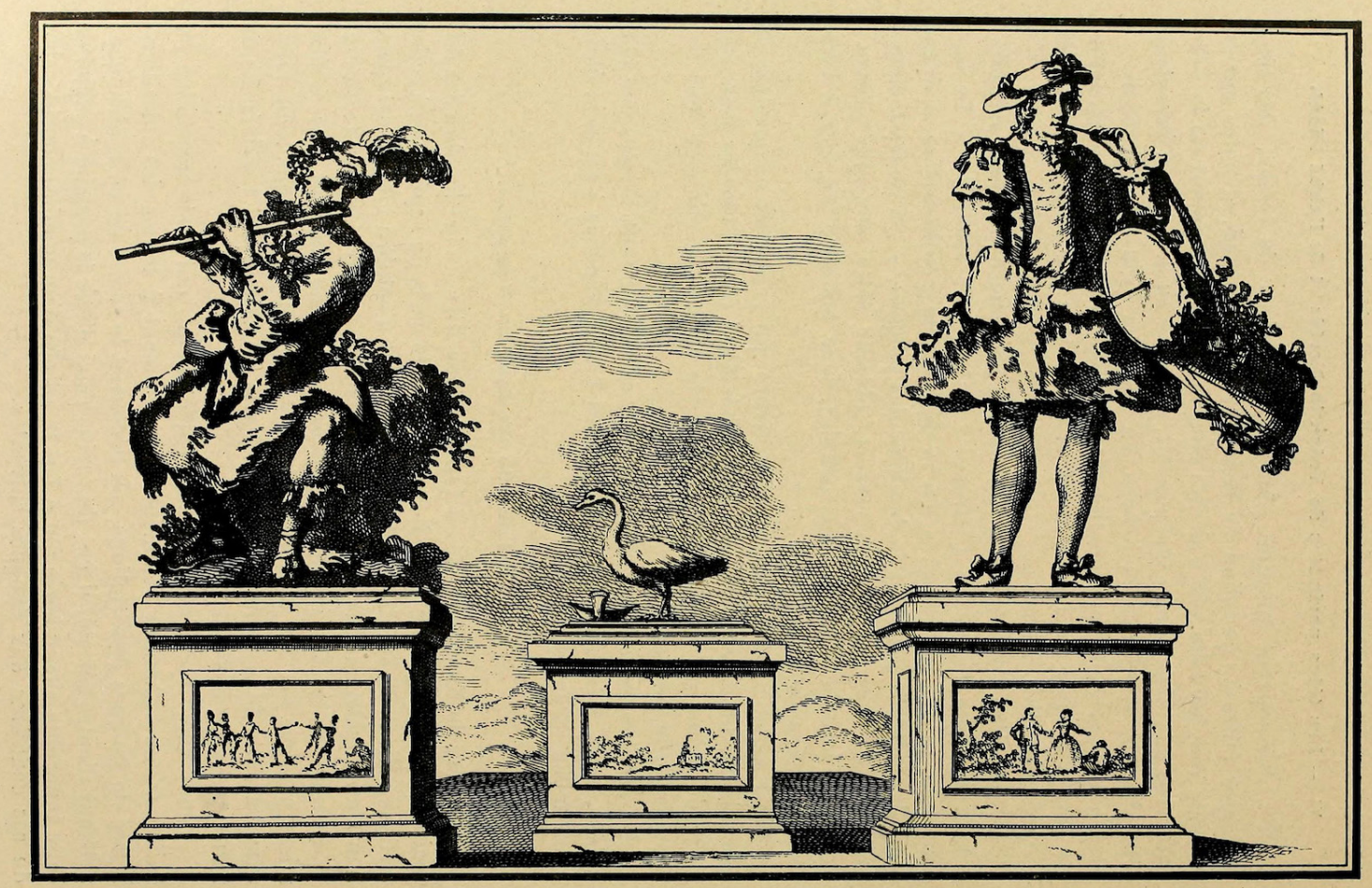

LE JOUEUR DE GALOUBET, LE CANARD ET LE JOUEUR DE TAMBOURIN piéces aUtomatiques constinUtes par Vaucanson.

Figure 1. Henry René D'Allemange, Le Jouer de Gloubet, Le Canard et Le Jouer de Tambourin - Pièces Automatiques Construites par Vaucanson in Histoire des jouets (Paris, 1902), 222. Public Domain.

Vaucanson's art, however, was also in his artifice. It was some time before his Canard was exposed to be a "canard": the "poop" was already hidden inside the duck by its human operator, awaiting the proper moment to be pushed out. Vaucanson's careful reproduction of the duck's anatomy, along with his written descriptions of the science of digestion and the physical and chemical processes hidden inside his machine, was all a sleight of hand meant to disguise the actual human hands and intervention necessary to complete the apparently autonomous and automatic process. The hoax begs the question, why would one even want robots to do such animal things as shit? Would not their freedom from biological needs and messes be a great advantage? And, even if authentic, why would we design our bots to do such useless, extraneous things as digest food unnecessary for their functioning? Vaucanson's invention would have been impressive for its naturalistic movement alone without simulating digestion. Why, then, did the inventor feel the need to disguise this one bit of human aid in the process? In this essay I appropriate journalist Brian Merchant's term "shitty automation" to bring to light the hidden human labor in automated processes, while also looking back to early automata to help us understand how such human (and animal) activities as defecating and making art came to be seen 
as open to automation, and how this is reflected in contemporary experiments with art-making artificial intelligence bots. Merchant coins the phrase to describe commonplace and often frustrating experiences with automated systems that work so poorly as to require a human assistant to help the machine along with its task, such as grocery self-checkout lines and phone menus, which tend to make experiences worse for users without necessarily lowering consumer costs or wasted time (while eliminating paid jobs for human laborers). ${ }^{5}$ Rather than focusing on systems that work so poorly as to need to be continually fixed by humans, I will adapt Merchant's term to think more broadly about how humans "stay in the loop" in automation beyond being the necessary adjuncts for making the systems work. We see evidence of hidden human hands as the authors of the algorithms, curators of data sets, and ghost-work taggers of metadata that fuel the functions of AI bots and machine learning algorithms. Moreover, I want to think about the shittyness of automation not just as a result of its inefficiencies, frustrations, or failures, but as a way of describing the human elements — our labor, bodies, biases, prejudices, and desires - that remain invisibly present even when these systems are working perfectly or functioning "like magic." In particular, I will look to how some of the nastier, abject bits of our culture are stowed inside these systems, placed there by human hands. In particular, I take up art-making AIs (and their human collaborators) that seek to compete with people in their least "useful" but also most human of labors. If creative acts are often thought to be the only province of human endeavor safe from the automation revolution, ${ }^{6}$ what are we to make of the current generation of imaging bots trained on Generative Adversarial Networks (GANs), such as the one made by Trevor Paglen that "hallucinates" "photographs"? The disturbing images created by these systems, I argue, do not show the threat of automation to this last refuge of singularly human endeavor. Rather, the alien and abject qualities of the images are manifestations of the human hands that have shaped them, and are gestures that point to our overwhelming desire to see the aesthetic productions of AIs fail.

\section{A REAL CANARD AND MERE BAGATELLE}

The renowned magician Jean-Eugène Robert-Houdin was just one of the observers who uncovered Vaucanson's dirty secret. A former clockmaker, he was fascinated by the technological skill needed to create this bit of artificial life. He went to see it in person at the Palais Royal in 1844 and was dutifully impressed. ${ }^{7}$ Sometime later, Robert-Houdin was asked to repair Canard Digérateur and uncovered its ruse. In his memoirs, he writes, "I found that the illustrious master had not disdained to have recourse to a trick which a conjuror would have been proud of. The digestion, so pompously announced in the memoir, was only a mystification - a real canard, in fact. Decidedly, Vaucanson was not only my master in mechanism, but I must bow before his genius for juggling." ${ }^{\prime \prime}$ Vaucanson had employed as much magic as machine in this automaton. Even his description of the digestive process contained an expert deflection. Instead of detailing the process of the "chemical laboratory" purported to be in the duck's guts, he made a provocative suggestion. This was intended to cause scientists and observers of the time to debate how digestion takes place in animals — whether by grinding or dissolution — rather than if his machine actually processed the food it consumed. ${ }^{9}$ 
Canard Digérateur was not the only animatronic hoax of its era. Better known and more confounding was Wolfgang von Kempelen's chess-playing mechanical Turk (1770), which seemed to simulate human intelligence, not just animal biology. This device consisted of an exotically dressed android sitting at a chess board that rested on a large wooden cabinet filled with gears and levers. [Figure 2] Much to the dismay of its human challengers, who included Napoleon Bonaparte, Benjamin Franklin, and Charles Babbage, the Turk did not just play chess, he most often won. ${ }^{10}$ The Turk, like Vaucanson's duck, was soon exposed to be a fraud, again one that aimed to disguise the human labor required for its marvelous performance. The automaton's preternatural chess playing abilities were owed to a rather long series of chess masters who were hidden inside the machine's base. [Figure 3] Ricky Jay, master of sleight of hand and scholar of the history of magic, described von Kempelen's device as one that relied on the standard routines of magicians to allay the skepticism of viewers:

To begin the demonstration, the doors and drawers of the cabinet were thrown open, preempting the audience's suspicion that a human operator was concealed within the machines. Gears and wheels were displayed as a candle was passed behind the dimmest parts of the interior. The Turk's robes were unceremoniously thrown over his head to allow for inspection from the rear, and even the interior of his physique was disclosed through a small door opened beneath his trousers. The entire structure was mounted on casters so that the cabinet could be revolved and viewed from all angles. ${ }^{11}$

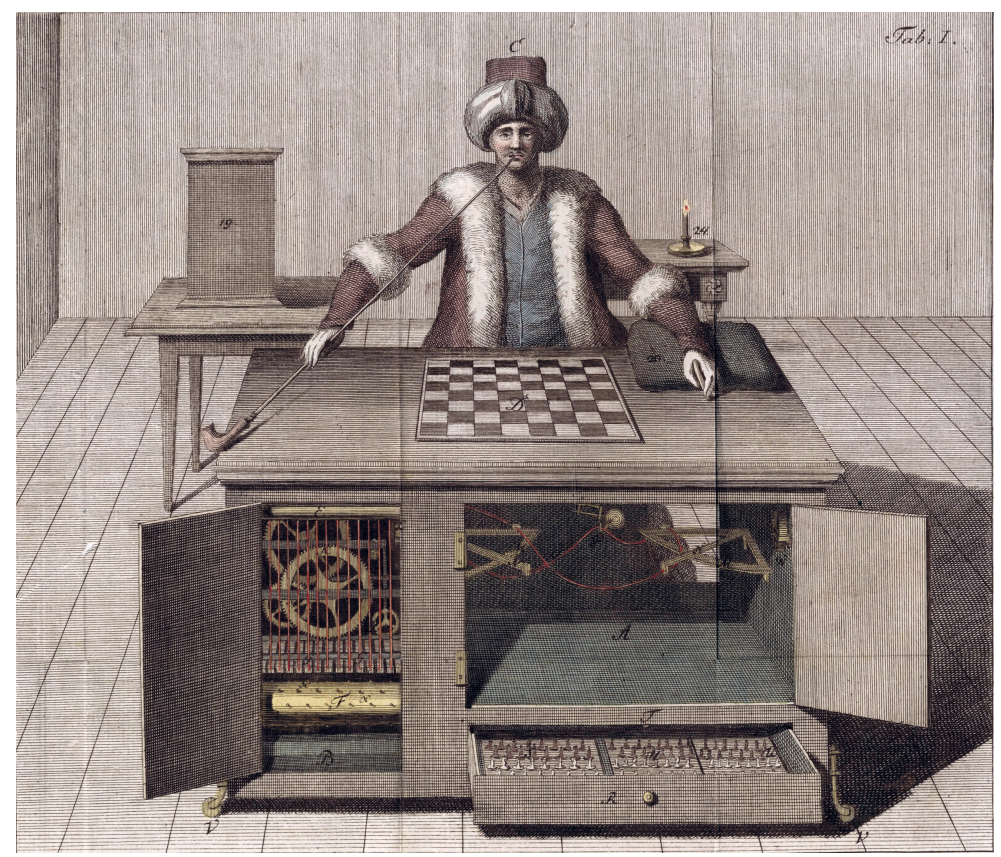

Figure 2. Joseph Racknitz, illustration of von Kempelen's Turk from Ueber den Schachspieler des Herrn von Kempelen und Dessen Nachbildung (Leipzig and Dresden, 1789), 63. Public Domain. 
Just as a magician might allow the audience to peek inside a hat before pulling out a rabbit, or inspect the casket before sawing a woman in half, von Kempelen (and those who toured the Turk after him $)^{12}$ made a spectacle of revealing the complex and apparently uninhabited interior. As he rotated the box, the hidden player shuttled himself into secret compartments, following a tight choreography that kept him continually hidden from view. During the match, von Kempelen used other tricks to divert the audience's attention. According to Jay, he busied himself with a separate, small wooden box, which he carefully guarded, not allowing anyone to see inside. The box had no purpose, but this bit of classic misdirection helped distract from the shuffling noises and lamp smoke coming from the base. ${ }^{13}$

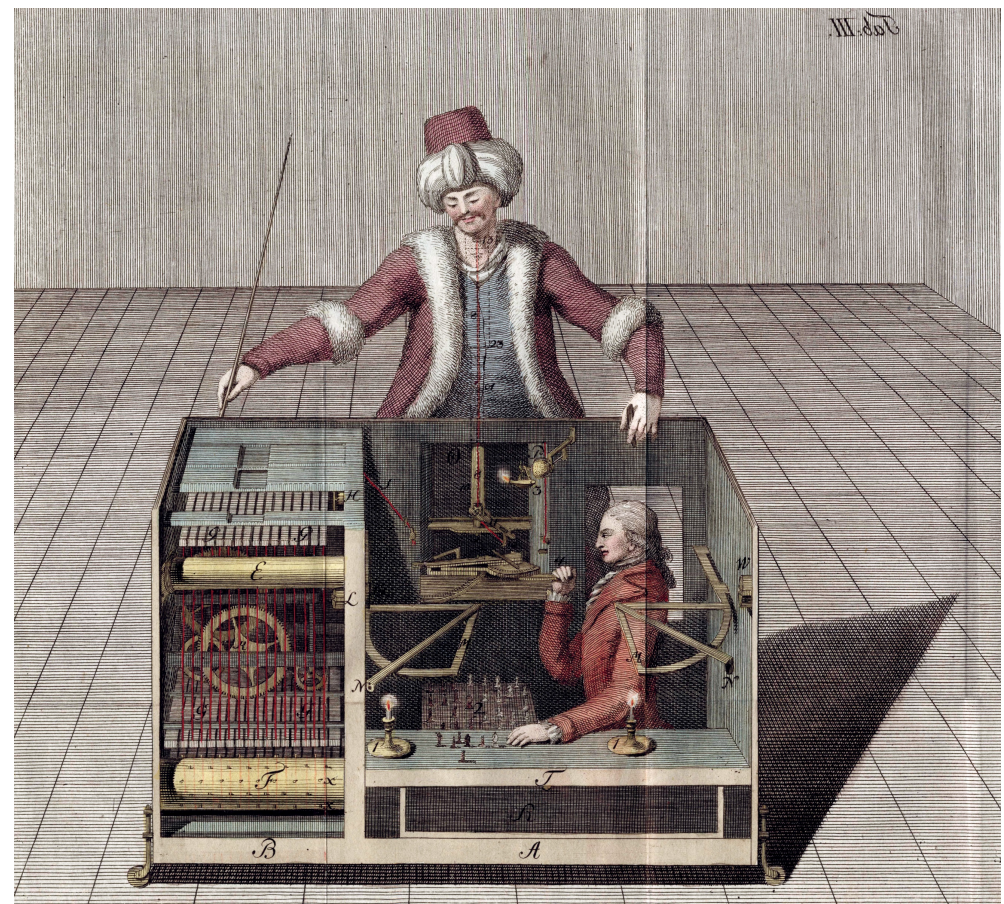

\section{Figure 3. Joseph Racknitz, illustration of von Kempelen's Turk from Ueber den Schachspieler des Herrn von Kempelen und Dessen Nachbildung (Leipzig and Dresden, 1789), 65. Public Domain.}

Despite the sensation and wonder it caused, von Kempelen derogatorily described his own invention as "mere bagatelle" - it was a trifle, a simple game, an act of little value or importance. What contemporary commenters may have taken as modesty or dissimulation was, perhaps, just simple honesty. To admit that Vaucanson's duck was a "canard" and von Kempelen's Turk "mere bagatelle," however, is not to disregard their technical and conceptual importance or to downplay the impact they and their inventors would have on the future of automation and labor. Jessica Riskin describes Vaucanson's inventions - authentic and fraudulent alike-as "philosophical experiments" that attempt "to discern which aspects of living creatures could be reproduced in 
machinery, and to what degree, and what such reproductions might reveal about their natural subjects."14 The importance of chess playing and defecation, in the eighteenth century at least, was that they, according to Riskin, seemed to be outside what it seemed possible to mechanize and thereby "provoked mechanicians who were interested in testing the limits of their crafts to become conjurers." 15 These early ventures into artificial life and artificial intelligence seem to be perfect tests for thinking through "Clarke's Three Laws," formulated by science fiction author and futurist Arthur C. Clarke:

"When a distinguished but elderly scientist states that something is possible he is almost certainly right. When he states something is impossible, he is very probably wrong."

"The only way of discovering the limits of the possible is to venture a little way past them into the impossible."

"Any sufficiently advanced technology is indistinguishable from magic."15

It may have seemed, and still might, that automating intelligence, creativity, gross anatomy, or biological processes would be impossible. These two automata could appear to prove it with their failures, but at the same time, by means of subterfuge and guile, they also blurred the boundary line between animal and machine by taking the perilous step into the impossible. They were able to do so because of Clarke's third law: just like legitimate technological advancements, Canard Digérateur and the Turk were so miraculous that they were indistinguishable from magic, or in this case, they were magic.

The inventions of Vaucanson and von Kempelen, two mechanics-turned-magicians, had great impacts on labor as much as on philosophy. The Turk has famously become a metaphor for "ghost work" in the current gig economy. In 2005, Amazon.com launched an online labor market which took its name from von Kempelen's automaton and, like the original, sought out human labor to secretly power its machines. Amazon's Mechanical Turk, or MTurk, for short, pays distributed workers to perform small tasks. This began as cleaning up copy on Amazon's website and soon expanded to an API (and spawned competitors) used by numerous companies to staff a wide assortment of tasks, including many with the express purpose of helping automated systems and AIs with little jobs that they cannot complete by the power of their own "intelligence."17 These labors, too, are "mere bagatelle" - typically trivial, "micro-tasks" for little compensation. Mary L. Gray and Siddarth Suri call the intentionally hidden human labor that powers apps, websites, and artificial intelligence systems "ghost work." ${ }^{\prime 18}$ Ghost work, in turn, helps fill in these gaps and simultaneously improves the AI's future performance by training the systems on the skills the workers are currently augmenting. This labor might take the form of tagging objects in images or cleaning up machine translated text. With each task they complete, then, the ghost laborers work toward eliminating the need for their help with that chore. Gray and Suri do not see this process, however, as a risk to the demand for future ghost work. Once ghost work helps perfect a given AI skill, "workers move on the next task engineers assign them that push the boundaries of automation," which then creates a new gap. ${ }^{19}$ We can expect, then, that humans will always be 
needed somewhere along the line to assist with even the most advanced automated tasks. In theory - and likely in practice - there will be no end to shitty automation.

Vaucanson's duck, too, led to revolutions in industrial labor and redefined what acts were considered to be open to automation and mechanization. Vaucanson's various automata, though failing to produce either shit or music, were far from useless, as they helped him reconceptualize what was intelligent labor and which tasks required human creativity. King Louis XV was so impressed with Vaucanson's abilities that he appointed the inventor "Inspector of Silk Manufacture." During his tenure, Vaucanson invented an early automatic, programmable loom (1747, later to be improved by Jacquard), which, Riskin argues, "took over a function that had hitherto been, not only human, but highly skilled." ${ }^{20}$ Canard Digérateur led to a process of opening the arts up to automation, and seeing these hitherto animal or human processes as programmable. The Turk, on the other hand, created an illusion of automation and accepted (although also disguised) the fact that some human labor will be required, no matter how autonomous actions might appear. Within these two objects and the histories they catalyzed we can see the origins of our current logic of automation and intelligence: all fields, all practices, regardless of how specifically human they might seem to be, will be open to automation, particularly via AI, and the human labor needed for those apparently autonomous systems will be hidden all along the way.

Merchant's examples of shitty automation involve poorly functioning, inefficient technology and the very visible and acknowledged presence of a human stepping in to help a system complete its task. Looking back to Vaucanson's and von Kempelen's automata, we can see another lineage for shitty automation: invisible, often unrecognized human labor makes systems function "like magic." "Working like magic," however, is a dangerous illusion, especially where automation is concerned. As M.C. Elish of Data \& Society writes, this common "refrain from the marketing materials of new technologies, especially those involving AI, ... implies impressive and seamless functionality and the means by which the effect was achieved is hidden from view or irrelevant. Yet, from another perspective, implying something works like magic focuses attention on the end result, denying an accounting of the means by which that end result was reached." ${ }^{21}$ This is troubling, Elish explains, because "AI seems to promise not only efficiency and insight, but neutrality and fairness," the latter being qualities often thought impossible to achieve with human input because of our implicit and explicit biases. $^{22}$ But as we have already seen with the example of MTurk, humans are often involved somewhere on the back end. As in Merchant's examples, humans are involved, and their labors add to the system's efficiency. What makes the systems "shitty," we shall see, are the ways in which cultural biases enter AI algorithms and data sets via these human factors, and how the lack of transparency and accountability in such systems, especially as they are "increasingly positioned as the answer to every question," often exacerbate the structural inequalities for vulnerable populations while masquerading as objective and rational. ${ }^{23}$

\section{HUMANS IN THE LOOP}

In computer science, augmentation and artificial intelligence initially seemed to be two distinct research fields. At the dawn of the computer age in the late 1960s, the two pursuits were "based on 
fundamentally different philosophies": one "sought to augment the human mind; and the other replace it." 24 When Douglas Engelbart demoed his oNLine System (NLS) (an event commonly known as "The Mother of All Demos") in 1968, which debuted new-fangled technologies and concepts such as a dedicated personal computer with a monitor for graphics and text editing, hyperlinked documents, an interactive computer "mouse," and the beginnings of an interconnected network of distant computers (ARPAnet, which soon became part of the technical basis of the Internet), it seemed that augmentation had, at least momentarily, won out over artificial intelligence. $^{25}$ The exciting future of computing that Engelbart presented, John Markoff explains, caused the tables to turn: "computer science, which had until then been primarily concerned with the esoteric problem of automating human intelligence, would never be the same." ${ }^{26}$ Most notably, the trends Engelbart began would keep humans "in the loop" in the future of computing, an impulse antithetical to the general goals of AI research of the era. "Engelbart," Markoff writes, "was a heretic, and it was from his heresy that personal computing grew." 27 Counterintuitively, perhaps, the AI boom - in both its power and ubiquity - could not take place without the technologies of augmentation Engelbart pioneered or without the copious amounts of data the humans using them would produce.

It is easy to see how the heretical technological future Engelbart outlined in his "Mother of All Demos" became the basis for the ghost-work-fueled AI revolution of today: web-connected workers stare at their screens, hold their mice, tag images, answer questions, link and upload documents that train AI. "Humans in the Loop," or HITL, is now a standard method in AI research to create machine learning models in which humans train, fine tune, and test algorithms. Even when systems operate fully autonomously, there were often humans in the loop somewhere earlier on in its development, as described above. It is this hidden human labor that helps our apps and automated systems "work like magic." But it is not just ghost work via Engelbart's augmentation tools that has aided rapid advancement of AI. ${ }^{28}$ The astounding improvements in AI in recent years are the result of in-machine learning, which could not succeed without the massive amounts of data present on the Internet, much of it uploaded, tagged, and defined by people in their leisure time "for free." 29 "The personal computer," Ethem Alpaydin writes, "was the first step in making computers accessible to the masses; it made digital technology a larger part of our lives and most important for [machine learning], allowed more of our lives to be recorded digitally." ${ }^{30}$ So began the process of converting our lives to data; sharing that information over the web, then turning it into training sets for machine learning algorithms. Until recently, before machine learning, AI was trained by programmers who defined what a bot knew and what it had to do. But the glut of information - audio, visual, and textual — produced, processed, stored, and shared online led to the development of learning programs that can produce their own models from ever-expanding data sets and can creatively generate new information and predictions from what they learn. 


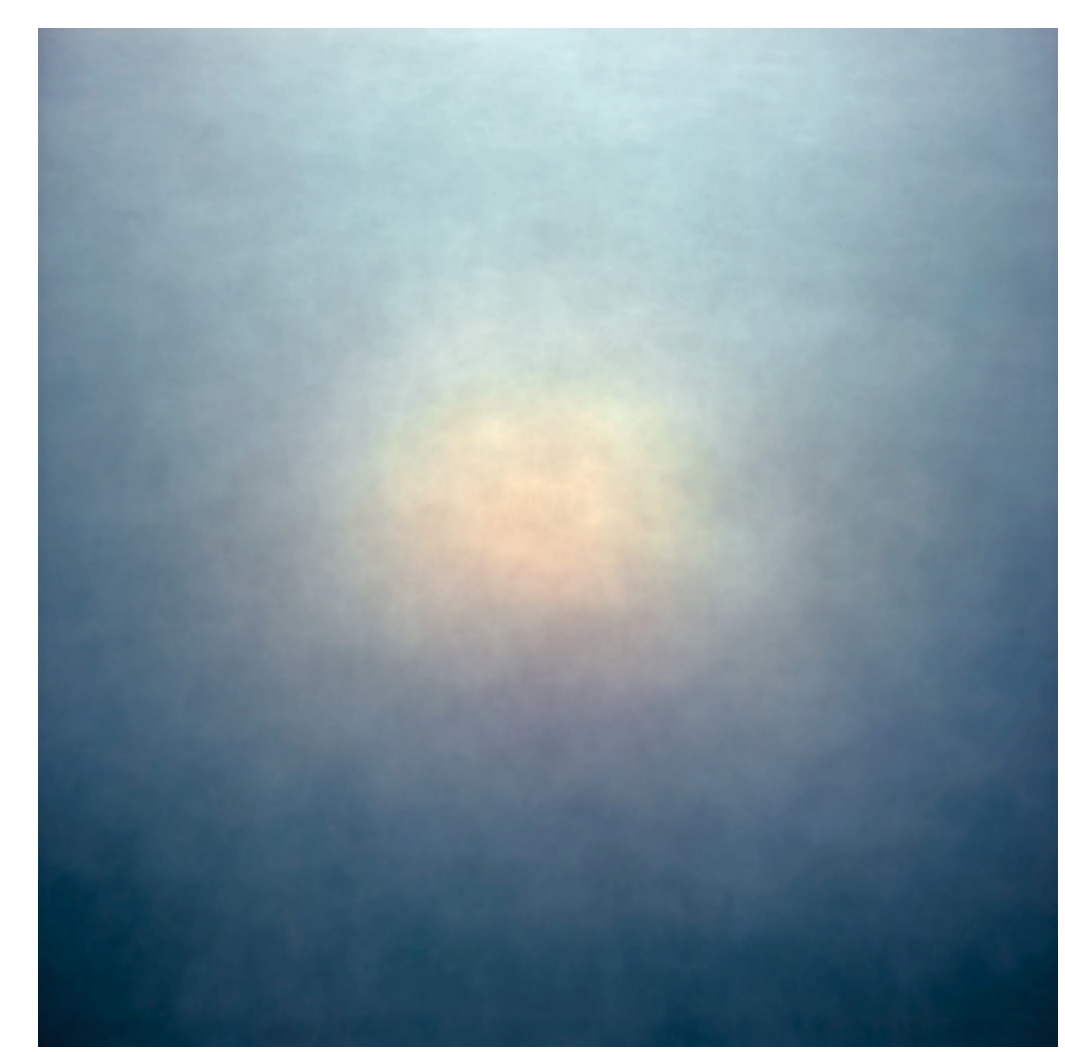

Figure 4. Trevor Paglen, The Shark, Linear Classifier (2018). Dye sublimation print, $48 x 48$ inches. Edition of 5 . Courtesy of the artist, Metro Pictures, New York and Altman Siegel, San Francisco.

Artist Trevor Paglen, whose work has continually sought to expose "invisible" elements of our military-industrial world - from secret bases to drones, undersea cables, and spy satellites - has recently begun figuring the "invisible images" that AIs make and show to each other in the processes of machine learning. "Human visual culture," Paglen explains, now comprises only a very small subset of "images" in circulation today. Many images, perhaps the vast majority of them "are now made by machines for other machines, with humans rarely in the loop." 31 Working with computer scientists at Stanford University, Paglen developed software that could intervene in the system to produce a human-readable, visual image of the machine learning data. Abstracted from the compilation of thousands of reference images in the popular ImageNet training set, Paglen's "photographs" manifest visions of how these linear classifiers understand the visual world. ${ }^{32}$ The resulting images are something like the AI's version of a Platonic ideal. Shark, Linear Classifier (2018) [Figure 4], for example, pictures the eponymous shark as hazy white-yellow glow hovering in the center of a murky blue-green expanse. Once so named, it is not hard to imagine how this generalized image of a shark derived from the sample set. With all of the vast variety of the more than 500 species of sharks - from hammerheads to tiger sharks, great whites, and enormous whale sharks - the idea of shark becomes, like the picture, very fuzzy. In Merchant's sense, this is a "shitty" image, in that it seems to fail informatically for the viewer and needs to be helped along by the title and the institutional exegesis in exhibition wall texts and artist statements. Without 
them, the picture is a lush but potentially unremarkable and meaningless abstraction. Labeled as such, however, the AI's soft abstraction becomes menacing: it is the flashing white belly of a predator spotted in one's peripheral vision, emerging from an empty and inhuman environment. Any failure to signify or cohere is not a flaw but Paglen's intentional solicitation of a technological sublime. ${ }^{33}$ It is an illustration of an othered nature, of a parallel world that is not "for us," that exceeds and disregards our ability to understand. Paglen's software and its "photographic" output allow one to see - to conjure from code-what this AI imagines a shark to be. No matter how unnerving one might take this gesture toward an inhuman technological singularity to be, the real threat is the very human biases and flaws that inform its evolved and automated vision.

Paglen's process of translating the data generated by the linear classifier into an image is an act of inserting a human into the loop of a system that otherwise would seem to be operating autonomously. The machine learning algorithm teaches itself based upon the available data. The image that results here is an intervention that allows for a moment of aesthetic judgement and philosophical contemplation. But the assertion that, up until this moment of mediation, there were no humans in the loop would have to be based on a very narrow view of the process. As in the Turk, human labor is invisibly hidden all along the way, and it sneaks bits of our human "shit"our tastes, our assumptions, our conscious and unconscious prejudices - into the system. All of the over fourteen million images on ImageNet use crowdsourced human labor from Amazon MTurk for "hand" annotation and quality control. ${ }^{34}$ Already in 2012, The New York Times reported that each year ImageNet "employs 20,000 to 30,000 people who are automatically presented with images to label, receiving a tiny payment for each one." 35 There is no true elimination of the human hand in these machine learning algorithms, despite their automation. While we might imagine that AI is objective and unbiased, operating above the fray of petty human irrationalities and cultural baggage, the opposite is true: machines may be doing the learning, but humans dictate what they can see. Human bias enters into the system when workers tag the images and curate the datasets, as well as when software applications are developed. As demonstrated in recent PR debacles, image recognition software might think that any person in a picture of a kitchen must be a woman if its image set skews that way, ${ }^{36}$ or that every black human face is actually a gorilla, if its image set isn't representative of the diversity of human skin tones. ${ }^{37}$ Neural networks, Paglen explains, "cannot invent their own classes; they're only able to relate images they ingest to images that they've been trained on. And their training sets reveal the historical, geographical, racial, and socio-economic positions of their trainers.... Formal concepts contain epistemological assumptions, which in turn have ethical consequences." 38 But AI does not just reproduce the biased information input, it learns to essentialize from it. Machine intelligence, Mateo Pasquinelli writes, "is not biomorphic - it will never be autonomous from humankind... Machine intelligence is sociomorphic, but not in a good way....We feed algorithms our racist, sexist, and classist biases and in turn they warp them further. As Marx knew, absent political action, machines do not just replace but amplify previous divisions of labor and social relations." 39 That is, when facial recognition algorithms tag dark-skinned faces as apes 
or when recruiting software automatically rejects applications by women, ${ }^{40}$ these are not glitches; these are clear manifestations of the humans in the machine.

\section{MONSTERS}

In another series of AI works Paglen actively seeks out and exploits the human traces in data sets and machine learning algorithms. Rather than producing a work that exposes what an AI might understand a shark, goldfish, sun, or stealth bomber to be, his Adversarially Evolved Hallucination series uses Generative Adversarial Networks (GANs) to categorize images and to imagine new ones. While this could be done with classes such as "shark," Paglen chooses far more idiosyncratic types to expose just how pervasively human culture affects the outcomes of these apparently independent and autonomous machines.

GANs employ two AIs that compete with one another. The first, the "discriminator" is trained to identify and class a certain type of image, as in the shark example above. A second system, the "generator" attempts to "evolve' recognizable images from random noise-almost like a hallucination" that the discriminator could accept as members of that class. ${ }^{41}$ Paglen produced his training sets, or "corpuses," to identify less stable categories of objects, such as metaphors for the horrors of capitalism ("Monsters of Capitalism") or symbolic items that appear in Sigmund Freud's Interpretation of Dreams. Rather than simply exposing AI as a manifestation of the unconscious biases of all of the various humans in the loop, Paglen intentionally curses his bots with neuroses or imbues them with poetic imaginations and tendencies toward metaphor. Vampire (Corpus: Monsters of Capitalism) (2017) [Figure 5] is an example of a picture that passed his discriminator's test for a likeness of the imaginary monster from folklore, literature, and film. The image, as a whole, looks little like Bella Lugosi's or Christopher Lee's Dracula or Al Lewis's Grandpa Munster: there are no fangs or widow's peaks, Victorian cravats, or rubied amulets. It looks barely human(oid) at all; but all of the essential elements are there, even if they are a bit out of order: a dark dilated pupil of a human eye appears through a hole in what might be a cascading curtain of silk or velvet; a bright white patch reminiscent of pancake makeup defines a potential cheekbone, and a viscous red and rusty orange spill slides down what could be a chin from the gaping ledge of an open maw; a bright silvery shine dominates the top of the picture, giving the effect of moonlight bouncing off pale skin or a slick swath of Brylcreem-ed hair. The result is not a rational “intelligence," but a flawed and nervous character that seems paranoid, seeing monsters in shadows or in just the barest indications of faces. 


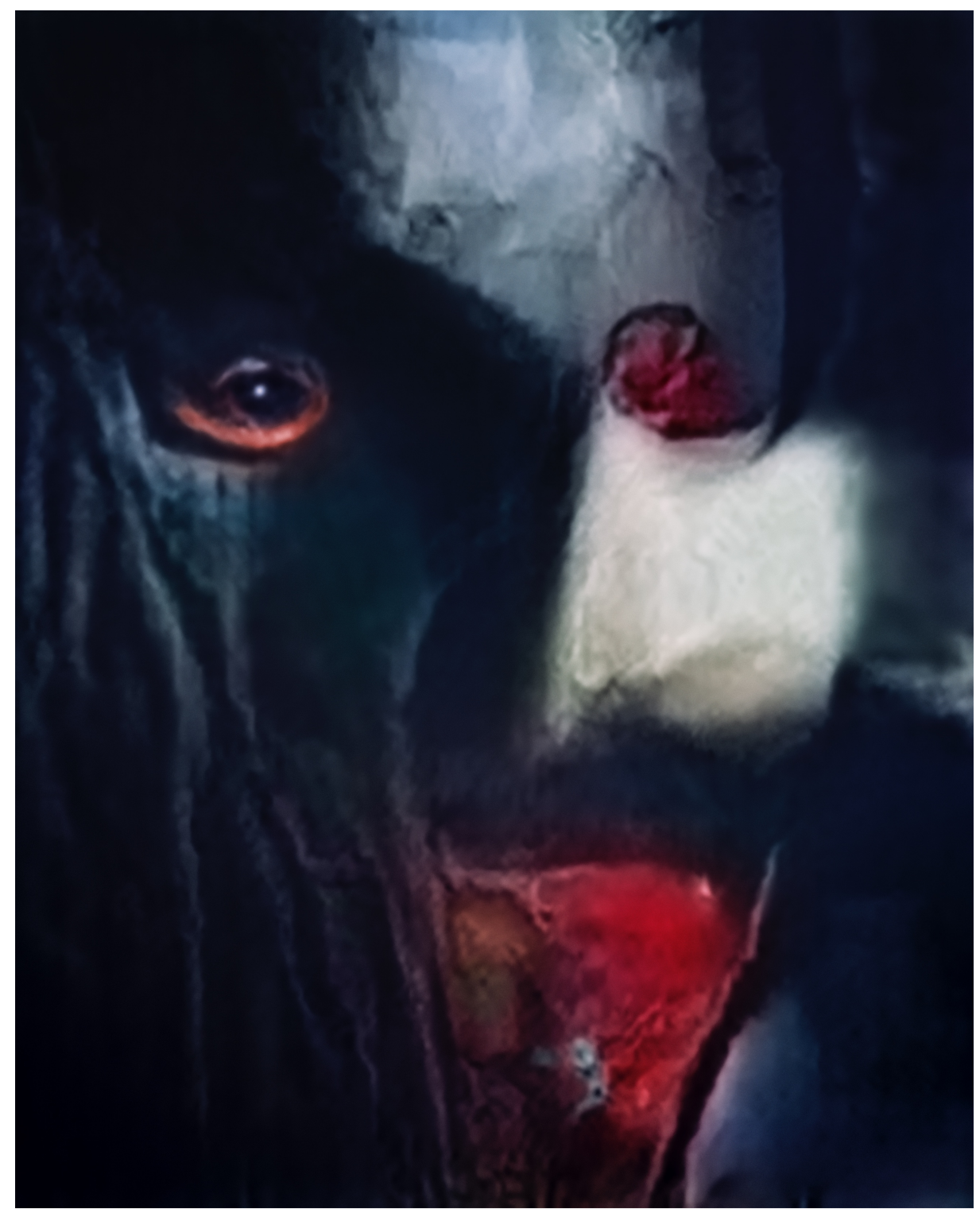

Figure 5. Trevor Paglen, Vampire (Corpus: Monsters of Capitalism), Adversarially Evolved Hallucination (2017). Dye sublimation print, $60 x 48$ inches. Edition of 5. Courtesy of the artist, Metro Pictures, New York and Altman Siegel, San Francisco. 


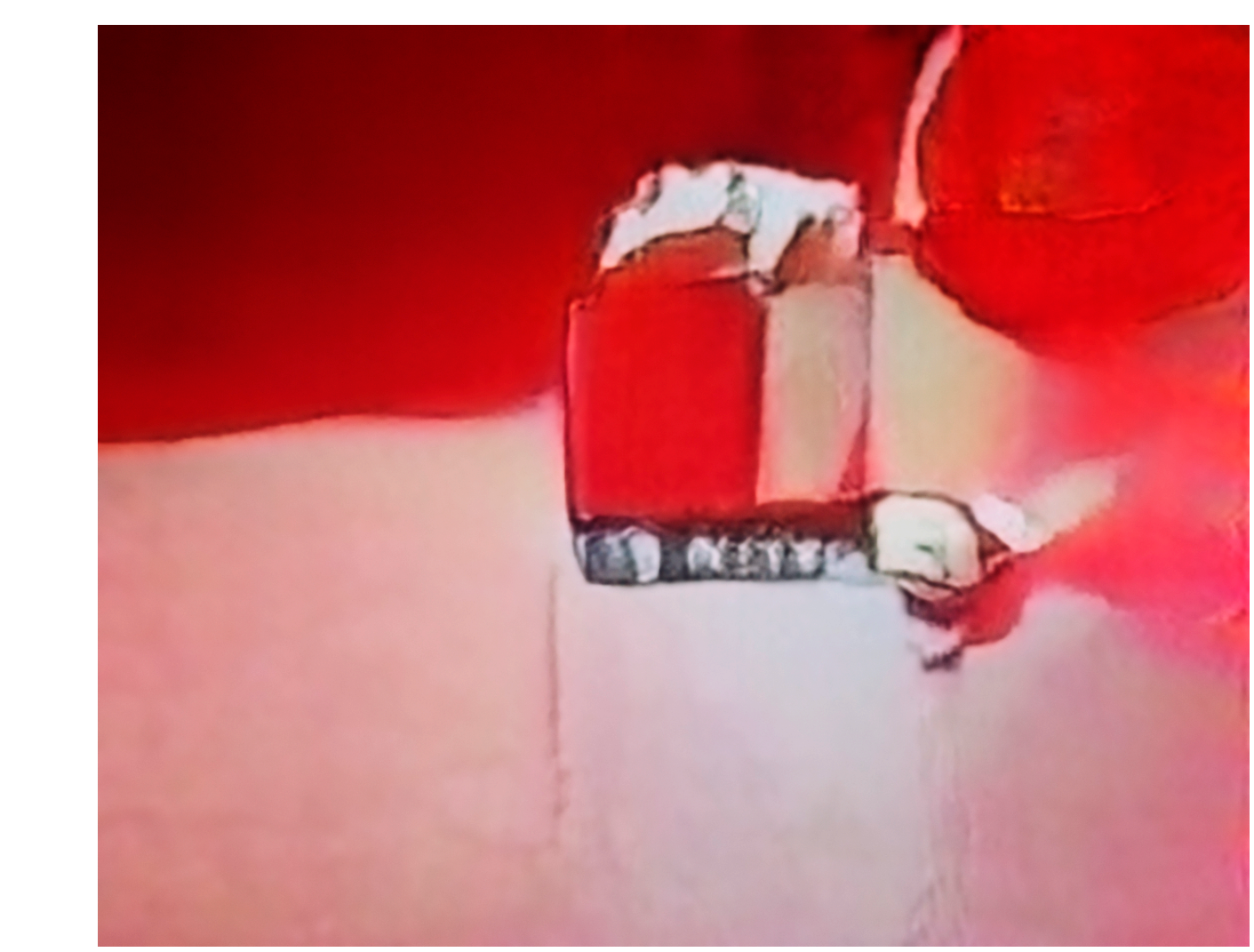

Figure 6. Trevor Paglen, False Teeth (Corpus: Interpretations of Dreams), Adversarially Evolved Hallucination (2017). $211 / 2 \times 267 / 8$ in. Edition of 5. Courtesy of the Artist and Altman Siegel, San Francisco.

Paglen pursues this line of intentionally programming for irrationality and neurosis by developing a GAN that parses and produces images based in Sigmund Freud's Interpretation of Dreams. Rather than looking at images and identifying specific individuals or the products and objects pictured, as many visual recognition systems that comb through our social media posts do, Paglen's sees only the items Freud marked as symbolically significant in his landmark text: it sees "injections, puffy faces, scabby throats, windows, ballrooms, ... mothers." ${ }^{, 2}$ False Teeth (Corpus: Interpretations of Dreams) (2017) [Figure 6], for example, presents the viewer with a painterly dreamscape that appears to owe some of its sensibility and palette to Philip Guston or Jean Fautrier. Mottled areas of white, pink and red softly collide at dark edges. There is a sense of flesh, if not figure, but only as half-remembered, repressed, or dreamed. A row of rough-hewn, blocky white and silver teeth rest in the center of the frame, eerily tucked into a small pocket of shadow. It seems impossible to imagine this image being useful in any way other than to mystify, communicate, interest, or delight. Paglen's photograph appears to be art made by one AI for another: the generator exposing the oddity of its secret flawed soul and the discriminator finding it relevant and meaningful. By embracing this very particularly human psychoanalytic subjectivity, and foregrounding his own presence and interventions in the process-from tagging the training set to choosing which of the generated images to print and display_-Paglen develops AIs that are "not 
useful in terms of capitalism or policing, the normal kinds of things you use artificial intelligence for." ${ }^{43}$ The images produced by Paglen's nervous bots, like those from his linear classifier series, also fail to cohere. As useless as these images might be, the twisted visions they produce are pleasing on yet another level - they seem to confirm and reinforce (if only by Paglen's own selection) the very human desire to remain superior and in control, which is particularly appealing in the era of "deep fakes" and other entirely convincing simulations enabled by machine learning and AI. To see these bots' confused productions, their inaccurate renderings and flawed imaginations, is to fulfill our own unspoken desires: if AIs are going to make art, let it be shitty.

Frankenstein may not have been one of Paglen's “monsters of capitalism," but certainly he has long been an apt reference when discussing automatons, automation, and AI. Mary Shelley subtitled her 1816 book "The Modern Prometheus" after the Titan who created man and gave them fire, an insult to the gods who then released Pandora and all her curses as punishment. Historians suspect that Shelley saw $18^{\text {th }}$-century automata, such as Pierre Jaquet-Droz's writing automaton soon before beginning Frankenstein. ${ }^{44}$ The name "Frankenstein" seems to cause continual confusion, as typically it is used to mistakenly refer to the "creature" in Shelley's book rather than to its creator, Dr. Frankenstein. Any quick search for a Halloween costume will underscore this tendency. Rossiter Johnson writes in his 1908 introduction to the story, "It is strange to note how well-nigh universally the term 'Frankenstein' is misused, even by intelligent persons, as describing some hideous monster; whereas Frankenstein is the name of the hero and supposed narrator of the story and not his terrible creation." 45 This "hero," however, gave birth to a being and then disowned and abandoned it; he refused to take responsibility for its actions or his role in them, or to teach it better ways. If one calls "the creature" Frankenstein, it is a proper assignment of parentage and influence. Perhaps it is right that both names should be flipped: the creature is Frankenstein and the doctor is, rightly, "the monster." Only in this apparent misnomer do we see clearly who was truly monstrous. Paglen, on the other hand, takes ownership of these monstrous images: they are created by a process that he put into motion. It is not a ceding of authorship or authority to a bot, but rather, Paglen explains, it is like the conceptual processes of Sol Lewitt, in which one is "just using a very different set of tools to make [art].... You're setting up elaborate sets of rules, and the images you're putting out are essentially the output of that system." ${ }^{46}$ Riskin, above, described the importance of Vaucanson's and von Kempelen's fraudulent automata as intellectual experiments aimed "to discern which aspects of living creatures could be reproduced in machinery, and to what degree, and what such reproductions might reveal about their natural subjects." Paglen's bots, too, indicate that one should focus attention not on the algorithms, but on the humans who had invisible hands in their creation. What one sees in the images created by AIs, then-Paglen's as well as those in our broader culture - is not an alien world but a dark mirror held up to our own. 


\section{ACKNOWLEDGEMENTS}

This work was supported in part by a grant from The Ohio State University's Public Humanities Collaborative and the Arts and Humanities Discovery Theme program, and an Ohio Arts Council Individual Excellence Award. I am particularly indebted to David Bates and Ken Goldberg for long-running conversations on these topics. Thank you to Altman Siegel Gallery for help with image reproductions and permissions. A special thank you to Jill Dawsey at the Museum of Contemporary Art San Diego for walking me through Trevor Paglen: Sights Unseen.

\section{ENDNOTES}

1. Gaby Wood suggests that Vaucanson may have used human skin on the android. Gaby Wood, Edison's Eve (New York: Anchor Books, 2002), 26.

2. Vaucanson quoted in Wood, Edison's Eve, 28.

3. The idea of art being "useless," and even defined by its very uselessness, has its roots in both Aestheticism and l'art pour l'art of the next century. On uselessness as a feature and function of art see, Peter Lamarque, "The Uselessness of Art," The Journal of Aesthetics and Criticism 68, no. 3 (Summer 2010).

4. I should note here that while digestion would have been "useless" in regard to the functioning of the robot (it did not claim to run on any of the energy produced by its supposed digestion), the perfect physical modeling of Canard Digérateur, including reproduction of every bone in the wing, for example, was academic in pursuit and led to advancements in several fields.

Vaucanson's work produced significant insights into acoustics, anatomy, respiration, the circulation of blood, and the development of artificial limbs. For more on the usefulness of Vaucanson's work see Jessica Riskin, “The Defecating Duck, or, The Ambiguous Origins of Artificial Life," Critical Inquiry 29, no. 4 (Summer, 2003): 616, 625.

5. Brian Merchant, "Why Self-Checkout Is and Always Has Been the Worst," Gizmodo, March 17, 2019, accessed August 1, 2019, https:/gizmodo.com/why-self-checkout-is-and-has-alwaysbeen-the-worst-1833106695.

6. See, for example, popular press articles such as Sarah Cascone, "Going to Art School Could Help Save Your Job from the Robots," Artnet, May 17, 2017, accessed July 15, 2019, https://news.artnet.com/art-world/arts-degree-jobs-automation-963125; or Dave Gershgorn, "Your art degree might save you from automation, an AI expert says," Quartz, May 16. 2017, accessed July 13, 2019, https:/qz.com/984749/your-art-degree-might-save-you-from-automationai-expert-kai-fu-lee-says/.

7. Jean-Eugène Robert-Houdin, Memoirs of Robert-Houdin Written by Himself, vol. 1 (London: Chapman and Hall, 1859), 174-175.

8. Ibid.

9. Wood, Edison's Eve, 28.

10. Riskin, "Defecating Duck," 620.

11. Ricky Jay, “The Automaton Chess Player," Jay's Journal of Anomalies (New York: Farrar Straus Giroux, 2001), 148. 
12. After von Kempelen's death in 1804, Johann Nepomuk Maelzel, a Viennese musician and inventor, acquired and toured The Mechanical Turk. Later, around 1940, Dr. John Kearsley Mitchell of Philadelphia showed the device. It was destroyed in 1854 when a fire consumed the Chinese Museum in Philadelphia, where the Turk then resided. Ibid., 152.

13. Ibid., 148.

14. Ibid., 148

15. Riskin, "Defecating Duck," 601. See also David Bates, "Cartesian Robotics," Representations 124, no. 1 (Fall 2013).

16. Arthur C. Clarke, "Hazards of Prophecy" in Profiles of the Future (New York: Holt, Reinhardt \& Winston, 1984), 29, 36.

17. Mary L. Gray and Siddarth Suri, Ghost Work (Boston and New York: Houghton Mifflin Harcourt, 2019), 2-7.

18. Ibid, ix

19. Ibid., xxii

20. Vaucanson's automated loom operated by means of a perforated, rotating cylinder that controlled the pattern. For a description of the mechanical process, see Riskin, "Defecating Duck," 627-628. For more on the connection to Jacquard, see Wood, Edison's Eve, 41. 21. M.C. Elish, "Don't Call AI 'Magic,'” Points Blog, Data \& Society, January 17, 2018, accessed January 8, 2019, https://points.datasociety.net/dont-call-ai-magic-142da16db408.

22. Ibid.

23. Ibid.

24. John Markoff, What the Dormouse Said: How Sixties Counterculture Shaped the Personal Computer Industry (New York \& London: Penguin Books, 2005), xi.

25. Ibid., 148-151.

26. Ibid., 159.

27. Ibid., 85 .

28. For an in-depth account how machine learning has advanced AI, see: Gideon Lewis-Kraus, "The Great AI Awakening," New York Times Magazine, December 14, 2016, accessed July 1, 2019, https://www.nytimes.com/2016/12/14/magazine/the-great-ai-awakening.html?auth=loginemail\&login=email.

29. The users of social media sites are the products of the site that serve the advertisers who pay the site for access to the users' feeds, as well as the purchasers of data generated by the users' actions on the site. This relationship has been well known for decades even if it seems new. It is the topic of Richard Serra's 1973 video Television Delivers People. For a contemporary discussion of this model in social media see, for example, Olivia Solodon, "You are Facebook's Product, Not Customer," Wired, September 21, 2011, accessed July 1, 2019, https://www.wired.co.uk/article/doug-rushkoff-hello-etsy; or Beth Daley, "If It's Free Online, You are the Product," The Conversation, April 19, 2018, accessed July 10, 2019, https://theconversation.com/if-its-free-online-you-are-the-product-95182; Kevin Granville, "Facebook and Cambridge Analytica: What You Need to Know as Fallout Widens," New York 
Times, March 19, 2018, accessed June 7, 2019, https://www.nytimes.com/2018/03/19/technology/facebook-cambridge-analytica-explained.html. 30. Ethem Alpaydin, Machine Learning (Cambridge, MA: The MIT Press, 2016), 5.

31. Trevor Paglen, "Invisible Images (Your Pictures Are Looking at You)," The New Inquiry, December 8, 2016, accessed June 23, 2019, https://thenewinquiry.com/invisible-images-yourpictures-are-looking-at-you/.

32. While Paglen refers to these works as "photographs," he does so with recognition that the term, technology, and practice have undergone a series of transformative shifts that make it now far removed from the previous concerns and essential features of analog photography as it has been theorized. On this topic, see his series of posts on the Still Searching blog for Fotomuseum: Trevor Paglen, "Is Photography Over?," https://www.fotomuseum.ch/en/explore/stillsearching/authors/26403 trevor paglen. It should be noted that the attempt to automate the process of making art is in no way a new idea. The history of $20^{\text {th }}$-century art has been, in one way or another, engaged with this idea, from Lázló Maholy-Nagy's Telephone Pictures from the early 1920s, to the industrial fabrication of Minimalist sculptures, to scored Fluxus performances or Sol Lewit's instruction-based drawings. This trend has been well documented; see, for example, Jack Burnham, "System Esthetics," Artforum, September 1968, 30-35.

33. For more on Paglen's regular invocation of the sublime see, Kris Paulsen, "Epilogue: Fingerprints," in Here/There: Telepresence, Touch and Art at the Interface (Cambridge: MIT Press, 2017), 183-186.

34. “About Image Net," ImageNet, accessed August 7, 2019, http://image-net.org/aboutoverview.

35. John Markoff, "Seeking a Better Way to Find Web Images," The New York Times, November 19, 2012, accessed August 4, 2019, https://www.nytimes.com/2012/11/20/science/for-webimages-creating-new-technology-to-seek-and-find.html.

36. Tom Simonite, "Machines Taught by Photos Learn a Sexist View of Women," Wired, August 21, 2017, accessed August 3, 2019, https://www.wired.com/story/machines-taught-by-photoslearn-a-sexist-view-of-women/.

37. Connor Dougherty, "Google Photos Mistakenly Labels Black People 'Gorillas," The New York Times, July 1, 2015, accessed July 31, 2019, https://bits.blogs.nytimes.com/2015/07/01/google-photos-mistakenly-labels-black-peoplegorillas/? $\mathrm{r}=1$.

38. Paglen, "Invisible Images (Your Pictures are Looking at You)."

39. Matteo Pasquinelli, "Abnormal Encephalization in the Age of Machine Learning," e-flux 75

(September 2016), accessed August 1, 2019, https:/www.e-flux.com/journal/75/67133/abnormalencephalization-in-the-age-of-machine-learning/.

40. Jeffery Dastin, "Amazon Scraps Secret AI Recruiting Tool That Showed Bias Against Women," Reuters, October 11, 2018, accessed July 10, 2019, https://www.reuters.com/article/usamazon-com-jobs-automation-insight/amazon-scraps-secret-ai-recruiting-tool-that-showed-biasagainst-women-idUSKCN1MK08G.

41. Trevor Paglen, "500 Words," Artforum, July 20, 2017, accessed June 22, 2019, https://www.artforum.com/interviews/trevor-paglen-talks-about-surveillance-ai-and-his-newwork-69919. 
42. Brian Boucher, "“This is the Project of a More Just World': Trevor Paglen on Making Art that Shows Alternative Realities," Artnet, June 11, 2018, accessed August 4, 2019,

https://news.artnet.com/art-world/trevor-paglen-interview-1299836.

43. Ibid.

44. Wood, Edison's Eve, xv.

45. Rossiter Johnson, The World's Great Stories in Brief, vol. 15. (New York: Author's Press, 1908), 238. Available through the Internet Archive,

https://archive.org/details/authorsdigestwor1915john/page/238.

46. Boucher, "This is the Project of a More Just World."”

\section{REFERENCES}

Alpaydin, Ethem. Machine Learning. Cambridge, MA: The MIT Press, 2016.

Bates, David. "Cartesian Robotics.” Representations 124, no. 1 (Fall 2013): 43-68.

Boucher, Brian. "“This is the Project of a More Just World': Trevor Paglen on Making Art That

Shows Alternative Realities," Artnet, June 11, 2018. Accessed August 14, 2019.

https://news.artnet.com/art-world/trevor-paglen-interview-1299836.

Burnham, Jack. "Systems Esthetics." Artforum (September 1968): 30-35.

Cascone, Sarah. "Going to Art School Could Help Save Your Job from the Robots." Artnet, May

17, 2017. Accessed July 15, 2019. https://news.artnet.com/art-world/arts-degree-jobsautomation-963125.

Daley, Beth. "If It's Free Online, You are the Product." The Conversation, April 19, 2018.

Accessed July 10, 2019. https://theconversation.com/if-its-free-online-you-are-theproduct-95182.

Dastin, Jeffery. "Amazon Scraps Secret AI Recruiting Tool that Showed Bias Against Women," Reuters, October 11, 2018. Accessed July 10, 2019. https://www.reuters.com/article/usamazon-com-jobs-automation-insight/amazon-scraps-secret-ai-recruiting-tool-thatshowed-bias-against-women-idUSKCN1MK08G.

Dougherty, Connor. "Google Photos Mistakenly Labels Black People 'Gorillas.” The New York Times, July 1, 2015. Accessed July 31, 2019.

https://bits.blogs.nytimes.com/2015/07/01/google-photos-mistakenly-labels-blackpeople-gorillas/? r=1.

Elish, M.C. "Don’t Call AI 'Magic,"” Points Blog, Data \& Society, January 17, 2018. Accessed January 8, 2019. https://points.datasociety.net/dont-call-ai-magic-142da16db408.

Gershgorn, Dave. "Your art degree might save you from automation, an AI expert says." Quartz, May 16. 2017. Accessed July 13, 2019. https://qz.com/984749/your-art-degree-mightsave-you-from-automation-ai-expert-kai-fu-lee-says/.

Granville, Kevin. "Facebook and Cambridge Analytica: What You Need to Know as Fallout Widens.” New York Times, March 19, 2018. Accessed June 7, 2019.

https://www.nytimes.com/2018/03/19/technology/facebook-cambridge-analyticaexplained.html.

Gray, Mary L., and Siddarth Suri. Ghost Work. Boston and New York: Houghton Mifflin Harcourt, 2019. 
ImageNet. "About Image Net." Accessed August 7, 2019. http://image-net.org/about-overview. Jay, Ricky. “The Automaton Chess Player.” In Jay's Journal of Anomalies. New York: Farrar

Straus Giroux, 2001.

Johnson, Rossiter. "Mary Wollstonecraft Godwin Shelley_Frankenstein: or, The Modern

Prometheus." In The World's Great Stories in Brief. Vol. 15, 238-244. New York:

Author's Press, 1908. Available through the Internet Archive,

https://archive.org/details/authorsdigestwor1915john/page/238.

Lamarque, Peter. "The Uselessness of Art." The Journal of Aesthetics and Criticism 68, no. 3

(Summer 2010): 205-214.

Lewis-Kraus, Gideon. “The Great AI Awakening.” New York Times Magazine, December 14, 2016. Accessed July 1, 2019. https://www.nytimes.com/2016/12/14/magazine/the-greatai-awakening.html?auth=login-email\&login=email.

Markoff, John. "Seeking a Better Way to Find Web Images." The New York Times, November 19, 2012. Accessed August 4, 2019. https://www.nytimes.com/2012/11/20/science/for-webimages-creating-new-technology-to-seek-and-find.html.

What the Dormouse Said: How Sixties Counterculture Shaped the Personal Computer Industry. New York and London: Penguin Books, 2005.

Merchant, Brian. "Why Self-Checkout Is and Always Has Been the Worst." Gizmodo, March 17, 2019. Accessed August 1, 2019. https://gizmodo.com/why-self-checkout-is-and-hasalways-been-the-worst-1833106695.

Paglen, Trevor. "500 Words.” Artforum, July 20, 2017. Accessed June 22, 2019.

https://www.artforum.com/interviews/trevor-paglen-talks-about-surveillance-ai-and-hisnew-work-69919.

. "Invisible Images (Your Pictures are Looking at You)." The New Inquiry, December 8, 2016. Accessed June 23, 2019. https://thenewinquiry.com/invisible-images-yourpictures-are-looking-at-you/.

"Is Photography Over?" Fotomuseum Blog, January 3-15, 2014. Accessed January 8, 2019. https://www.fotomuseum.ch/en/explore/still-earching/authors/26403 trevor_paglen

Pasquinelli, Matteo. "Abnormal Encephalization in the Age of Machine Learning," e-flux 75

(September 2016). Accessed August 1, 2019. https://www.e-

flux.com/journal/75/67133/abnormal-encephalization-in-the-age-of-machine-learning/. Simonite, Tom. "Machines Taught by Photos Learn a Sexist View of Women." Wired, August 21, 2017. Accessed August 3, 2019. https://www.wired.com/story/machines-taught-byphotos-learn-a-sexist-view-of-women/.

Solodon, Olivia. "You Are Facebook's Product, Not Customer," Wired, September 21, 2011. Accessed July 1, 2019. https://www.wired.co.uk/article/doug-rushkoff-hello-etsy.

Riskin, Jessica. "The Defecating Duck, or, The Ambiguous Origins of Artificial Life," Critical Inquiry 29, no. 4 (Summer, 2003): 599-633.

Robert-Houdin, Jean-Eugène. Memoirs of Robert-Houdin Written by Himself. Vol. 1. London: Chapman and Hall, 1859.

Wood, Gaby. Edison's Eve. New York: Anchor Books, 2002. 


\section{AUTHOR BIO}

Kris Paulsen is an associate professor in the Department of History of Art and Program in Film Studies at The Ohio State University. She is the author of Here/There: Telepresence, Touch, and Art at the Interface (Cambridge: MIT Press, 2017), which received the 2018 Anne Friedberg Award for Innovative Scholarship from the Society for Cinema and Media Studies (SCMS). 